\title{
The Ventilatory Response to Cholecystokinin Tetrapeptide in Healthy Volunteers
}

\author{
M.A. Katzman, B.Sc., M.D., FRcPc, J. Duffin, Ph.D., J. Shlik, M.D., Ph.D., and
} J. Bradwejn, M.D., FRcPc

The cholecystokinin (CCK) system, which has been shown to interact with both the panicogenic and respiratory systems, provides an interesting mechanism to further evaluate the central chemoreceptor and its effect on panic attack sensitivity. Intravenous CCK, a naturally occurring neuropeptide in the brain, has been found to induce the emotional and somatic symptoms of panic in both Panic Disorder (PD) and Normal Control (NC) subjects in a dosedependent and reproducible fashion. To induce these effects, lower doses of intravenous CCK are required in the PD patients, relative to the NC subjects potentially suggesting that endogenous alterations in the CCK system may be contributing to the development of PD.

Intravenous administration of CCK-4 in association with panic also results in subjective dyspnea, that is, diminution in vital capacity without an effect on the respiratory resistance. CCK-4 also causes a significant increase in tidal volume and minute ventilation but has no effect on breathing frequency. These observations suggest that a CCK-B receptor agonist may be acting as a respiratory stimulant, exerting its effect on anxiety through a direct effect on respiration.

This study represents an examination of the specific effects of CCK-4 on the central chemoreceptor response.

The study used a modified rebreathing technique, which accurately measures the ventilatory response to carbon dioxide in terms of both threshold and sensitivity. This technique requires the subject to rebreathe from a bag containing a hyperoxic and hypercapnic gas mixture resulting in rapid equilibration between alveolar gas and arterial blood. Use of a hyperoxic gas allows for the preferential examination of the central chemoreflexes (sensitive to $\mathrm{CO}_{2}$ ) with little if any effect of the peripheral (oxygen sensitive) chemoreflexes.

After significant training, 15 healthy control subjects were assigned via a double blind procedure to receive an intravenous injection of placebo or CCK-4, using a between-subjects design. A between-subjects comparison was undertaken for the injection run (run \#3) between subjects receiving the CCK-4 injection and those receiving the placebo injection. As well, a within-subject comparison was undertaken to compare the results of the run following the injection (run \#3) vs. the previous run when no injection took place (run \#2).

No significant differences were noted between subjects who received CCK-4 as compared with placebo for: basal or sub-threshold ventilation, threshold $\mathrm{CO}_{2}$ resulting in a change in ventilation, or sensitivity of the central chemoreflex, regardless of whether a panic attack did or did not take place. In addition, within the group receiving the CCK-4 challenge, no significant differences were noted during run \#3 (received the CCK-4 injection) and a prior run where no injection took place (run \#2).

From the Centre for Addiction and Mental Health-Clarke Division (MK), and Department of Physiology (JD), University of Toronto, Department of Psychiatry, University of Tartu (JS), and Royal Ottawa Hospital, University of Ottawa (JB).

Address correspondence to: Martin A. Katzman, BSc, MD, FRCPC, Anxiety Disorder Clinic Centre for Addiction and Mental Health, 250

College Street, Toronto, Ontario M5T 1R8 Canada, Tel.: (416) 979-6819, Fax: (416) 979-6853, E-mail: martin_katzman@camh.ne

Received March 29, 2001; revised September 10, 2001; accepted December 19, 2001.

Online publication: 12/21/01 at www.acnp.org/citations/Npp122101219.

Data presented: American Psychiatric Association Annual Meeting “The Clinician” Washington DC. May 15-20. 
We conclude that CCK-4 does not act to induce panic by altering the central $\left(\mathrm{CO}_{2}\right.$ sensitive) chemoreceptor. [Neuropsychopharmacology 26:824-831, 2002]
(C) 2002 American College of Neuropsychopharmacology. Published by Elsevier Science Inc.
KEY WORDS: Cholecystokinin-B receptor; Cholecystokinintetrapeptide (CCK-4); Read rebreathing test; Panic attack; Central chemoreflex; False suffocation alarm hypothesis

In trying to characterize the pathophysiology of Panic Disorder (PD), a number of panic inducing agents (challenges) have been used to provoke panic attacks (PA) in order to investigate PAs in the laboratory setting.

One important challenge procedure has invoked the panic response using intravenous administration of cholecystokinin tetrapeptide (CCK-4) in order to activate the cholecystokinin (CCK) system. Activation of the CCK system has been shown to result in changes in both the panicogenic and respiratory functions, providing a clue to the potential interaction of these two systems in the pathophysiology of PD. What makes the CCK challenges even more interesting in terms of potentially localizing an area of lesion accounting for the symptoms in PD, is that the various forms of CCK also represent naturally occurring neuropeptides (Harro et al. 1995) found in high concentration in the cerebral cortex, the limbic system and brainstem of the mammalian brain (Harro et al. 1995; Bourin et al. 1995).

Support for the role of the CCK system in PD first came from studies in which cholecystokinin-B receptor agonists, cholecystokinin-tetrapeptide (CCK-4) and pentagastrin, were systemically administered to both NC and PD patients. These studies revealed that these agents were able to induce the emotional and somatic symptoms of panic in both PD and NC subjects in a dose-dependent and reproducible fashion (Bourin et al. 1995; Bradwejn et al. 1991a, 1992), with lower doses required to induce these effects in the PD patients, relative to the NC subjects (Bradwejn et al. 1991a,b, 1992). This finding is not surprising, given the fact that NCs lack a history of panic attacks and therefore would be imagined to have higher threshold of susceptibility to spontaneous as well as induced PA relative to PD patients. The enhanced sensitivity to CCK agonists evident in PD patients may thus be attributable to endogenous alterations in the CCK system.

Specific interactions between the CCK and respiratory systems were reported by Pagani et al. (1982) and later by Bates and Bradwejn, (1995) who reported an increased respiratory minute volume (independent of respiratory rate) following the activation of the CCK system, suggesting a potential interaction of the CCK and respiratory systems. Furthermore, later studies revealed that this effect could be blocked by a prior dose of proglumide (a specific CCK receptor antagonist) (Gillis et al.
1983) and that the source of these effects of CCK-8S was specifically localized to the medullary regions involved in breathing (Hurlé et al. 1988).

The first studies in humans assessing the effect of CCK-4 on respiration were undertaken by Shlik et al. (1997), who reported that intravenous administration of CCK-4 resulted in subjective dyspnea in relation to a diminution in vital capacity without an effect on respiratory resistance. Subsequently, Bradwejn et al. (1998) reported that CCK-4 caused a significant increase in tidal volume and minute ventilation, without an effect on breathing frequency. These observations suggested that CCK agents may act as respiratory stimulants, potentially exerting their effect on anxiety through a direct effect on respiration.

Still, while the CCK theory has shown much promise, the lack of efficacy of CCK antagonists to date in terms of their ability to relieve panic in humans, continues to provide a significant challenge to this theory.

Other sources of evidence have also focused on the ventilatory system in relation to panicogenicity. These panicogenic challenges have focused on the response to inhaled $\mathrm{CO}_{2}$ and the enhanced sensitivity for having a panic attack in PD patients. This enhanced sensitivity to $\mathrm{CO}_{2}$ has lead to the development of the " $\mathrm{CO}_{2}$ hypersensitivity" (Nutt and Lawson 1992; Gardner 1996). Hypersensitivity to $\mathrm{CO}_{2}$ and other challenges (e.g. lactate, bicarbonate) was extended by Klein (1993) to formulate a "False Suffocation Alarm" hypothesis. According to this theory, inhalation of a hypercapnic gas mixture results in PAs in PD patients and, much less frequently, in healthy comparison subjects (NC). However in a manner similar to the CCK challenges, PD patients would be expected to respond earlier than NCs, with the PAs experienced after hypercapnic inhalations being quite similar to those experienced spontaneously (Papp et al. 1993a,b, 1995). According to this theory, increased sensitivity of the central chemoreceptor may result in the increased sensitivity of PD patients to inhaled $\mathrm{CO}_{2}$. Still no specific anatomical system has been associated with this theory.

The $\mathrm{CO}_{2}$ challenges that have been performed have been undertaken either by taking one or two deep breaths of $35 \% \mathrm{CO}_{2}$ (Perna et al. 1994, 1996; Verburg et al. 1995) or by slow rebreathing of $5-7 \% \mathrm{CO}_{2}$ in air (Papp et al. 1995). In order to assess the specifics of the central chemoreceptor, Read (1967) undertook to modify the slow rebreathing paradigm by having the subject rebreathe from a smaller than previously used bag under hyperoxic conditions. This allowed for the establishment of a more 
rapid constant relationship between the end-tidal partial pressure of carbon dioxide and that of the body tissues and the central chemoreceptors. Further modifications of Read's protocol were undertaken by Duffin and McAvoy (1988), who started the rebreathing after a period of hyperventilation, thereby lowering body stores of carbon dioxide below the central-chemoreflex threshold and thus allowing the measurement of the centralchemoreflex threshold.

In this study we used the Duffin and McAvoy (1988) modifications of the Read Rebreathing Protocol in order to investigate whether CCK- 4 acts to directly alter the sensitivity or threshold of activity of the central chemoreflex.

\section{METHOD}

Fifteen, non-smoking subjects (12 males and 3 females), not meeting criteria for any medical or psychiatric illness, were enrolled in the study. All subjects were evaluated using a psychiatric interview, the Structured Clinical Interview for DSM-IV Axis I Disorders. Subjects also received a medical history and physical examination and laboratory tests (including blood hematology and chemistry, urinalysis, urine drug screen, EKG and pregnancy test for females) and performed and completed the Symptom Checklist 90 (SCL-90) prior to entering the study. All subjects provided written informed consent and had normal findings on physical examination and all laboratory assessments. Subjects meeting criteria for any Axis I diagnosis or scoring higher than a 7 on the SCL-90 were excluded from entry into the study. Subjects were told to refrain from caffeine or ethanol intake for $48 \mathrm{~h}$ prior to the study day, and refrain from eating after midnight prior to the study day.

The modified Read Rebreathing apparatus, previously described by Duffin and McAvoy (1988), was used with the addition of a computer controlled feedback system to maintain hyperoxic conditions throughout the experiment. The entire apparatus was calibrated before each subject's experimental session. An oximeter probe (Bruel and Kjaer, model 8852 ) was placed on the subject's index finger in order to monitor heart rate and oxygen saturation. The subject wore a nose clip throughout the experiment and breathed via a mouthpiece connected to a $\mathrm{Y}$ valve (Collins P-319; $80 \mathrm{ml}$ dead space). This valve allows subjects to be switched from room air to the rebreathing bag. A tube attached to the valve sampled the air breathed at the mouth in order to monitor closely the end-tidal values of carbon dioxide and oxygen (Bruel and Kjaer, anesthetic monitor type 8852). The rebreathing bag, approximately 5 liters, was enclosed in a rigid container and was connected to a dry rolling seal spirometer (Morgan Spiroflow, model 130) by a short length of wide bore $(37 \mathrm{~mm})$ tubing so that ventilation could be monitored on a breath-by-breath basis. The bag was filled with a gas mixture with a $\mathrm{CO}_{2}$ partial pressure of $42 \mathrm{mmHg}$ and oxygen partial pressure of $200 \mathrm{mmHg}$, with remainder of nitrogen.

CCK-4, consisting of an amino acid chain of tryptophanmethionine-aspartate-phenylalanine- $\mathrm{NH}_{2}$ (TRP-MET-ASPPHE-NH2), was prepared to provide a dose of $50 \mathrm{mcg}$ of CCK-4 in $2.5 \mathrm{ml}$ of sodium chloride $0.9 \%$ solution. For placebo infusion, an equivalent volume of saline was used. Subjects were blind to the contents of the infusion.

On the study day, the subjects underwent three experimental trials. Each trial began with the subject being asked to hyperventilate room air for $5 \mathrm{~min}$ through the $Y$ valve to lower their end-tidal partial pressure of carbon dioxide to $20-24 \mathrm{mmHg}$. Subsequently, the subject was switched to the rebreathing bag and asked to take three deep breaths. This was undertaken to ensure that the end-tidal partial pressure of carbon dioxide $\left(\mathrm{P}_{\mathrm{ET}} \mathrm{CO}_{2}\right)$ and oxygen $\left(\mathrm{P}_{\mathrm{ET}} \mathrm{O}_{2}\right)$ in the bag, lungs and arterial blood quickly equilibrated with the mixed venous partial pressure, thus providing an accurate indicator of $\mathrm{P}_{\mathrm{ET}} \mathrm{CO}_{2}$ and $\mathrm{P}_{\mathrm{ET}} \mathrm{O}_{2}$ at ventral medullary (central) and carotid body (peripheral) chemoreceptive regions. Adequate equilibration was ensured by the observation of a plateau in the end-tidal partial pressure of carbon dioxide. After a short period of time during which a horizontal portion of the Ventilation versus $\mathrm{PCO}_{2}$ graph was observed, a sudden change in the slope was noted after which ventilation rose linearly with $\mathrm{PCO}_{2}$. The trial was terminated at an end-tidal $\mathrm{PCO}_{2}$ of $60 \mathrm{mmHg}$. At this time the subject was switched back to room air and allowed to recover for several minutes. Each trial ended with a thirty-minute rest period. The first trial was a training run in which the subject was introduced to the rebreathing apparatus, and the hyperventilation technique. The second trial was undertaken to get a baseline level of activity. During this run, an assessment of the endtidal partial pressure of $\mathrm{CO}_{2}\left(\mathrm{P}_{\mathrm{ET}} \mathrm{CO}_{2}\right)$, from onset of rebreathing to the level of $\mathrm{P}_{\mathrm{ET}} \mathrm{CO}_{2}$ when the ventilation begins to rise, was ascertained. This allowed for the determination of the time of the injection in the third run (just prior to the $\mathrm{P}_{\mathrm{ET}} \mathrm{CO}_{2}$ at which ventilation increased in the previous run). On-line breath-by-breath data acquisition generated an on-screen-ventilatory response, with rise in ventilation and corresponding $\mathrm{P}_{\mathrm{ET}} \mathrm{CO}_{2}$ available for each of the runs, allowing determination of ventilatory breakpoint $\mathrm{P}_{\mathrm{ET}} \mathrm{CO}_{2}$-central chemoreflex threshold.

In the third trial the participating subjects were randomly assigned to undergo treatment with either CCK-4 or placebo in a double-blind fashion. An antecubital catheter with a 3-way stopcock was inserted on the right arm with an intravenous attachment, to keep the vein open for the double-blind bolus administration of either 
$2.5 \mathrm{ml} 0.9 \%$ sodium chloride solution (placebo), or of CCK-4 (50 mcg in $2.5 \mathrm{ml}$ of sodium chloride $0.9 \%$ solution). While rebreathing under hyperoxic conditions maintained by computer control, the subjects received a double-blind bolus administration of either $2.5 \mathrm{ml}$ of $0.9 \%$ sodium chloride (placebo), or of CCK-4 $(50 \mathrm{mcg}$ in $2.5 \mathrm{ml}$ of sodium chloride $0.9 \%$ solution). The time at which the subject received the injection was determined during the previous run, to be prior to activation of the central chemoreflex (rapid change in the slope of ventilation vs. $\mathrm{P}_{\mathrm{ET}} \mathrm{CO}_{2}$ graph).

In addition, if the subject noted any symptoms following the injection, they were to notify the research team of the onset and offset of symptoms through a previously rehearsed hand movement. Following completion of the Test Phase, the subject was asked to retrospectively assess the severity of their symptoms on the DSM-IV derived PSS (Panic Symptom Scale).

\section{STATISTICAL ANALYSIS}

Breath-by-breath values of ventilation and the end-tidal partial pressures of oxygen and carbon dioxide were analyzed. First a plot of ventilation versus end-tidal partial pressure of carbon dioxide was undertaken to assess for the carbon dioxide threshold response of the central chemoreflex of each subject. For each subject, the first breakpoint was interpreted as the threshold for the central-chemoreflex ventilatory response to $\mathrm{CO}_{2}$. Constant ventilation equal to the mean was then fitted to the segment below the threshold and was interpreted as the basal ventilation. A reduced major axis was fitted to the segment above the threshold and its slope was interpreted as the central-chemoreflex sensitivity of response to $\mathrm{CO}_{2}$ for that particular subject.

Thus, for each subject the following parameters were determined: basal ventilation, central-chemoreflex threshold and sensitivity. These were calculated for each of the three potential levels of the independent variable: (a) hyperoxic condition with no injection; (b) hyperoxic condition with placebo injection; and (c) hyperoxic condition with CCK-4 injection.

A 1-way ANOVA was undertaken to examine for differences between the placebo and CCK- 4 groups in terms of the number of symptoms, sum of symptoms (severity), the time to onset of symptoms, duration of symptoms during the challenge. Differences in panic rate were examined using the compare proportions test (Z-test).

\section{RESULTS}

No significant differences were noted between the placebo and CCK-4 group in terms of age, sex or descriptive differences.
In terms of subjective symptoms, 2 of 8 subjects receiving CCK-4 and 0 of 7 receiving Placebo responded with a panic attack. A 1-way ANOVA revealed significant differences between the Placebo and CCK-4 groups during the third run, in terms of number of symptoms $(p<.003)$, sum of symptoms $(p<.002)$. The time to onset of symptoms $(p<.001)$ and the duration of symptoms $(p<.001)$ also were significantly different as there were no panic attacks in the placebo group. No significant differences were noted in panic rate between the placebo and CCK-4 groups.

The changes in ventilation with time during rebreathing test 2 (no-injection) and 3 (injection) are compared in Figure 1 for a typical subject receiving CCK-4 (Figure 1, upper panel) and a subject receiving placebo (Figure 1, lower panel). The mean response for all sub-
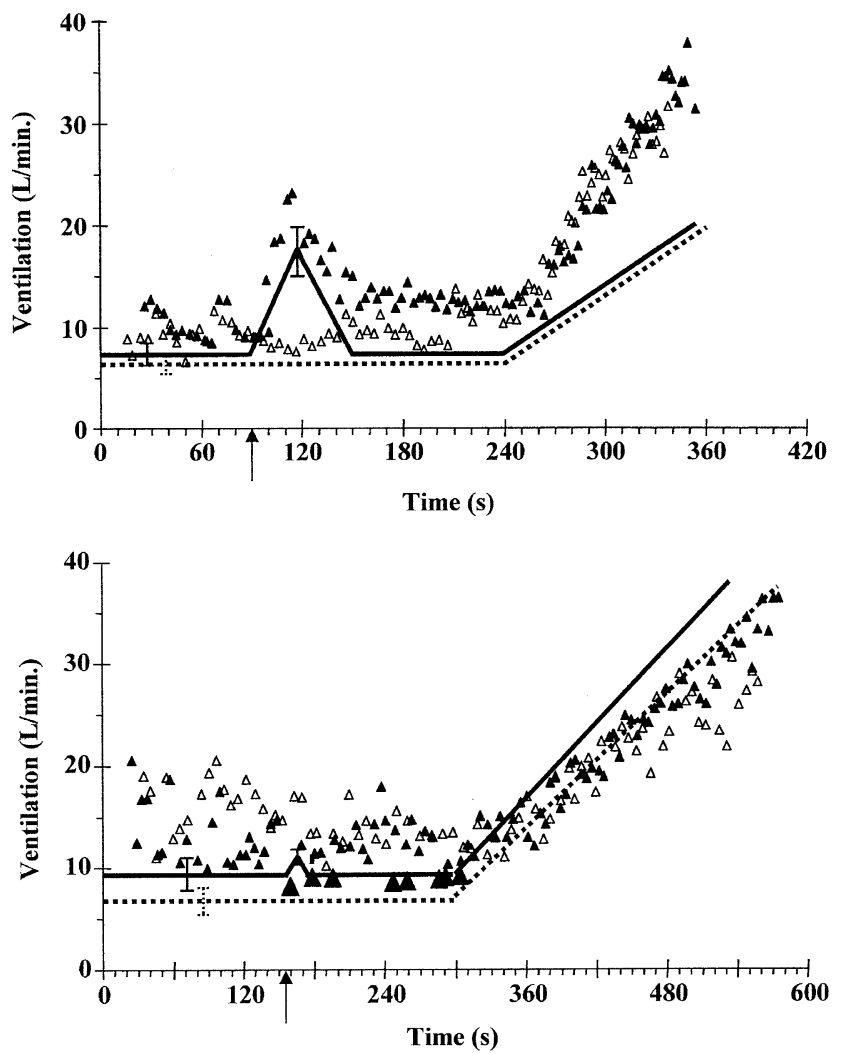

Figure 1. A comparison of the changes in ventilation with time during rebreathing tests 2 (no-injection, open triangles) and 3 (injection, filled triangles) for a typical subject receiving CCK-4 (upper panel) and a subject receiving placebo (lower panel). The lines indicate the group mean responses (injection, solid; no injection, dashed). They represent the basal ventilation and rise of ventilation with time, with the response to the injection indicated as a triangle whose base is the mean response duration and whose height is the mean change in ventilation. For the purposes of illustration, the start of the group mean response was the same as the individual response. The arrow indicates the time of injection. 
jects is superimposed with a mean-fit line (injection, solid line; no-injection, dashed line). The CCK-4 injection produced a mean (SE) transient increase in ventilation of 11.0 (2.4) liters/min in eight subjects, whereas the placebo injection produced a mean increase of only 1.9 (0.5) liters/min in seven subjects. These changes were significantly different $(p<.003, t$-test).

Similarly, the changes in heart rate with time during rebreathing tests 2 (no-injection) and 3 (injection) are compared in Figure 2 for a typical subject receiving CCK-4 (Figure 2, upper panel) and a subject receiving placebo (Figure 2, lower panel). Similarly, the mean response for all subjects is superimposed with a mean-fit line (injection, solid line; no-injection, dashed line). The CCK-4 injection produced a mean (SE) transient increase in heart rate of 28.7 (3.7) beats/min in eight subjects, whereas the placebo injection produced a mean increase
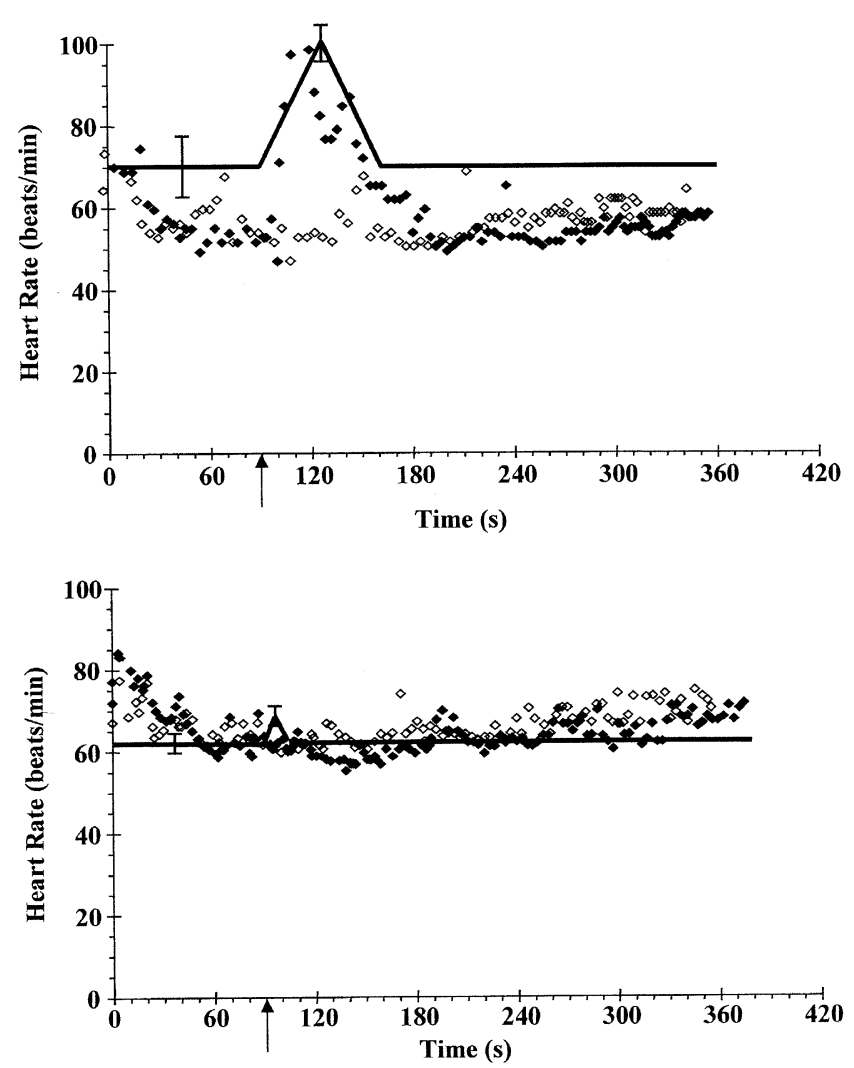

Figure 2. A comparison of the changes in heart rate with time during rebreathing tests 2 (no-injection, open diamonds) and 3 (injection, filled diamonds) for a typical subject receiving CCK-4 (upper panel) and a subject receiving placebo (lower panel). The subjects are not the same as in Figure 1. The lines indicate the group mean responses (injection, solid). They represent the basal heart rate, with the response to the injection indicated as a triangle whose base is the mean response duration and whose height is the mean change in heart rate. For the purposes of illustration, the start of the group mean response was the same as the individual response. An arrow indicates the time of injection. of only 6.6 (2.4) beats/min in seven subjects. These changes were significantly different $(p<.001, t$-test).

Figure 3 shows a comparison of the ventilation versus end-tidal $\mathrm{CO}_{2}$ graphs for rebreathing tests 2 (no injection) and 3 (CCK-4 injection) for one subject representative of the general findings. Mean responses for all subjects are superimposed (injection, solid line; noinjection, dashed line). Neither the threshold nor the slope of the response above threshold differed between these tests, although they were markedly different between subjects. Table 1 compares the basal ventilation, thresholds and slopes between tests 2 (no injection) and 3 (injection) for the subjects receiving CCK-4, as well as for the subjects receiving placebo. No significant differ-
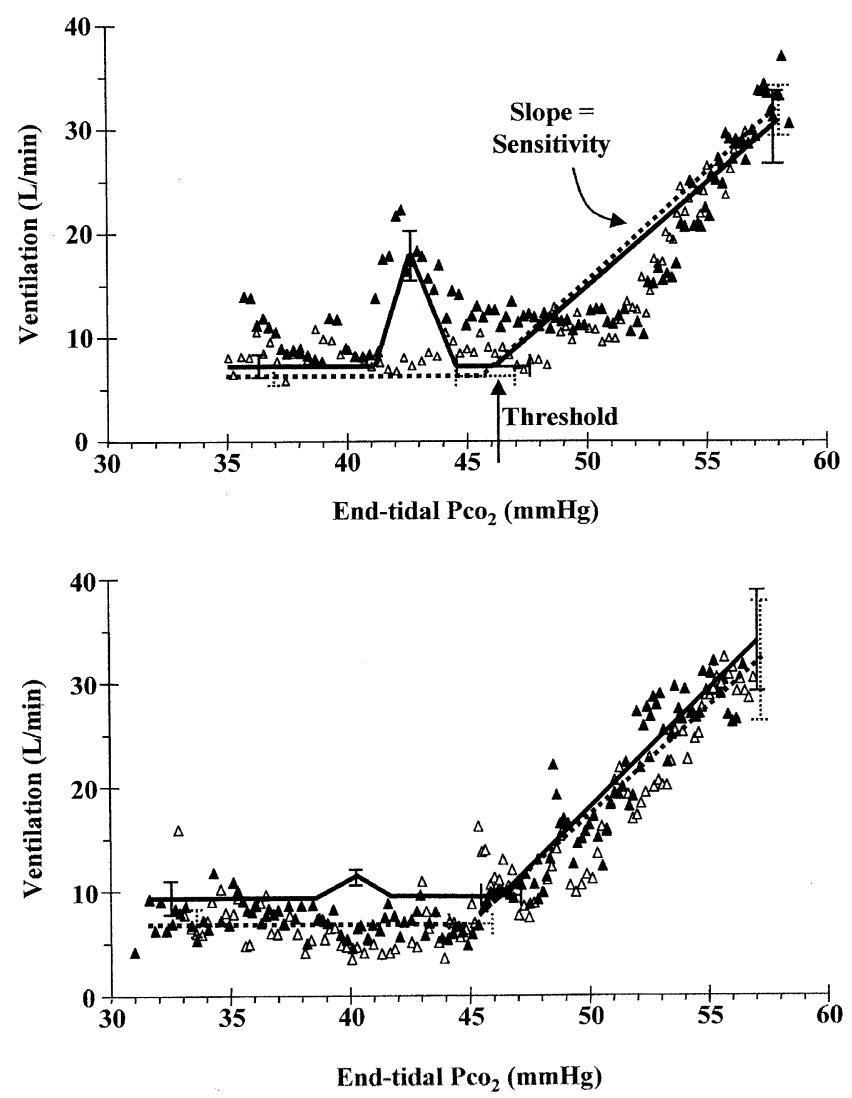

Figure 3. A comparison of the changes in ventilation with end-tidal partial pressure of carbon dioxide during rebreathing tests 2 (no-injection, open triangles) and 3 (injection, filled triangles) for a typical subject receiving CCK-4 (upper panel) and a subject receiving placebo (lower panel). The subjects are not the same as in Figure 1 or Figure 2. The lines indicate the group mean responses (injection, solid; no injection, dashed). They represent the basal ventilation and rise of ventilation with carbon dioxide after a threshold is exceeded, with the response to the injection indicated as a triangle whose base is the mean response duration and whose height is the mean change in ventilation. For the purposes of illustration, the start of the group mean response was the same as the individual response. 
Table 1. Characteristics of the Central Chemoreflex: Mean (SE)

\begin{tabular}{|c|c|c|c|c|c|}
\hline & & \multicolumn{2}{|c|}{ CCK-4 Group } & \multicolumn{2}{|c|}{ Placebo Group } \\
\hline & & No Injection & Injection & No Injection & Injection \\
\hline Basal Ventilation & $\mathrm{L} / \mathrm{min}$ & $5.7(1.0)$ & $6.4(0.7)$ & $7.0(0.9)$ & $9.6(1.1)$ \\
\hline Threshold & $\mathrm{mmHg}$ & $45.2(1.0)$ & $45.2(1.2)$ & $45.0(0.9)$ & $46.0(0.8)$ \\
\hline Sensitivity & $\mathrm{L} / \mathrm{min} / \mathrm{mmHg}$ & $1.9(0.1)$ & $1.8(0.2)$ & $2.1(0.5)$ & $2.3(0.5)$ \\
\hline
\end{tabular}

ences were found for basal ventilation, threshold or slope between tests 2 and 3 for each group, and there were no significant differences between groups (1-way ANOVA).

\section{DISCUSSION}

Our findings indicate that CCK-4, despite inducing a panic alarm and a significant increase in tidal volume and minute ventilation, does not appear to have any direct effect on the central chemoreceptor. Thus it must be concluded that the CCK-4 induced changes in panic and respiration do not result directly from the effect of the CCK-4 on the central chemoreceptor, but rather secondary to the panic itself. The credibility of this conclusion rests largely on the validity of the method employed and its acceptance as an accurate index of the central chemoreflex threshold and sensitivity of response to $\mathrm{CO}_{2}$.

The modified Read rebreathing test (Duffin and McAvoy 1988), though a widely used and accepted tool of chemoreflex function in respiratory physiology (Duffin and McAvoy 1988; Mohan and Duffin 1997; Mahamed et al. 2001; Duffin et al. 2000; Mahamed and Duffin 2001), has not, until now, been used to investigate panic etiology. Central to Read's (1967) original rebreathing technique is the ability to measure end-tidal $\mathrm{CO}_{2}$ levels at ventral medullary (central) chemoreflex regions from breath-by-breath samples. This is achieved by allowing equilibration in $\mathrm{CO}_{2}$ levels between lung, alveoli, arterial, and tissue levels, whereby an accurate central chemoreflex sensitivity response to $\mathrm{CO}_{2}$ is obtained. While Read's original technique is an excellent measure of chemoreflex sensitivity, it does not allow measurement of chemoreflex threshold to $\mathrm{CO}_{2}$; extrapolating the ventilatory slope to the $\mathrm{PCO}_{2}$-axis does not give a measure of the chemoreflex threshold of response to $\mathrm{CO}_{2}$, because the intercept is also dependent on the sensitivity. Yet, it is the chemoreflex threshold of response to $\mathrm{CO}_{2}$ that may be of more interest in PD-associated $\mathrm{CO}_{2}$-hypersensitivity, and particularly Klein's (1993) "False Suffocation Alarm Theory." The modification of Read's technique included a prior hyperventilation to eliminate body $\mathrm{CO}_{2}$ levels well below chemoreflex threshold, in effect eliminating the chemoreflex drive to breathe in the early, hypocapnic phase of the rebreathing test, until a threshold rise of ventilatory slope, the true chemoreflex threshold to $\mathrm{CO}_{2}$.

Several other concerns, unrelated to the rebreathing method used, should be noted. The challenge stimuli $\left(\mathrm{CO}_{2}\right.$ and $\left.\mathrm{CCK}-4\right)$ were applied to a non-clinical population. It has been suggested that the anxiety/panic system is different in a PD population compared with NC, and this is a valid point to keep in mind. However, Klein's (1993) "False Suffocation Alarm" hypothesis proposes that all subjects, NC inclusive, have a "suffocation alarm" and are therefore susceptible to panic in response to panicogen-induced panic, albeit with less frequency. In that regard, study of the central chemoreceptors in this population is warranted. Furthermore, recent work by Gorman et al. (2001) concludes that PAs, whether present in PD subjects or NC, once induced present in a similar manner irrespective of presence or absence of PD diagnosis. Also, this work was limited to a study of the central chemoreceptors, with carotid body (peripheral) chemoreceptor contribution removed from the ventilatory response by the hyperoxic condition of the rebreathing test. It is possible that CCK-mediated differences in ventilatory response are related to interactions at the carotid body and therefore not observed in our result.

Our findings represent a disentangling of the respiratory chemoreflex and panic systems. Thus, the CCK system, while activating the panic system and therefore directly affecting breathing, did not have any direct effects on the detection of carbon dioxide by the central chemoreflex.

Thus our results suggest that the CCK system functions in a closely related but independent manner with respect to the respiratory system. That is, while both CCK- 4 and $\mathrm{CO}_{2}$ activate the panic alarm and stimulate the respiratory system, they do so in ways that are independent of each other. Thus, CCK induction of panic and the associated respiratory increase does not appear to take place through an alteration of the central chemoreflex.

Thus it would appear that there may exist two distinct but closely linked neuroanatomical systems that respond to signals of potential danger. One system would respond to an elevation in $\mathrm{CO}_{2}$ by activation of the res- 
piratory chemoreflex with associated sensation of suffocation. This in term might activate a second alarm system to induce fight or flight from potentially dangerous settings where danger exists. Perhaps this system is the one sensitive to the CCK-4 challenge. This conclusion is forecast and supported by recent research by Gorman et al. (2001), with our direct measure of the central chemoreflex activity as direct proof of this. However, some have argued that an alarm system involving the fight or flight response would involve activation of the typical fear response associated with hypothalamicpituitary-adrenal axis (HPA-axis) activation (Coplan and Klein 1996). These authors point out that, while HPAaxis activation is observed with CCK-induced panic (Sinha et al. 1999), it is not observed with $\mathrm{CO}_{2}$ /lactateinduced or spontaneous panic and thus not a necessary feature of panic. The results presented here may in fact support this systems dichotomy of differential neuroanatomical routes of panic induction with CCK versus $\mathrm{CO}_{2}$. Still, one might also imagine that these two systems would be interconnected in a manner that goes both ways with the activity of the respiratory system also indirectly but not directly affected through activation of the CCK system.

Our results indicate that CCK does not affect the central chemoreflex response to $\mathrm{CO}_{2}$. As such, these data support the conclusions of Gorman et al. (2001) that PD patients may have a lower threshold for activation of the fight or flight anxiety alarm (CCK-4 sensitive) rather than exaggerated chemoreflex response to carbon dioxide. Perhaps a comparison of the responses of central chemoreceptors in PD patients as compared with NCs would be helpful in our further understanding of the pathogenesis of PD.

\section{ACKNOWLEDGMENTS}

We would like to thank Mr. Lukasz Struzik for his considerable assistance with the preparation of this manuscript.

\section{REFERENCES}

Bates JH, Bradwejn J (1995): Ventilatory response to cholecystokinin tetrapeptide in anaesthetized dogs. Neuroreport 6:2513-2517

Bradwejn J, Koszycki D, Annable L, Couetoux du Tertre A, Reines S, Karkanias C (1992): A dose-ranging study of the behavioural and cardiovascular effects of CCKtetrapeptide-induced in panic disorder. Biological Psychiatry 32:903-912

Bradwejn J, Koszycki D, Bourin M (1991a): Dose ranging study of cholecystokinin in healthy volunteers. J Psychiatr Neurosci 16:91-95

Bradwejn J, Koszycki D, Shriqui C (1991b): Enhanced sensitivity to cholecystokinin-tetrapeptide in PD: clinical and behavioral findings. Arch Gen Psychiatry 48:603-607
Bradwejn J, LeGrand JM, Koszycki D, Bates JH, Bourin M (1998): Effects of cholecystokinin tetrapeptide on respiratory function in healthy volunteers. Am J Psychiatry 55:280-282

Bourin M, Malinge M, Vasar E, Bradwejn J (1995): Two faces of cholecystokinin: anxiety and schizophrenia. Fundam Clin Pharmacol 10:116-126

Coplan JD, Klein DF (1996): Pharmacological probes in panic disorder. In Westenberg HGM, Den Boer JA, Murphy D (eds), Advances in the Neurobiology of Anxiety Disorders. New York, John Wiley and Sons Ltd.

Duffin J, Mohan R, Vasiliou P, Stephenson R, Mahamed S (2000): A model of the chemoreflex control of breathing in humans: model parameter measurement. Resp Physiology 120:13-26

Duffin J, McAvoy GV (1988): The peripheral-chemoreceptor threshold to $\mathrm{CO}_{2}$ in man. J Physiol (Lond) 406:15-26

Gardner WN (1996): The pathophysiology of hyperventilation disorders. Chest 109:516-534

Gillis RA, Quest JA, Pagani FD, Souza JD, Da Silva AM, Jensen RT, Garvey TQ 3d, Hamosh P (1983): Activation of central nervous system cholecystokinin receptors stimulates respiration in the cat. J Pharmacol Exp Ther 224:408-414

Gorman JM, Kent J, Martinez J, Browne S, Coplan J, Papp LA (2001): Physiological changes during carbon dioxide inhalation in patients with panic disorder, major depression and premenstrual dysphoric disorder: evidence for a central fear mechanism. Arch Gen Psychiatry 58:125-135

Harro J, Vasar E, Koszycki D, Bradwejn J (1995): Cholecystokinin in panic anxiety disorders. Advances in Biology Psychiatry 1:235-262

Hurlé MA, Dierssen MM, Morin-Surun MP, Oceja C, Flórez J (1988): Respiratory actions induced by cholecystokinin at the brainstem level. Peptides 9:809-815

Klein DF (1993): False suffocation alarms, spontaneous panics, and related conditions. Arch Gen Psychiatry 50:306-317

Mahamed S, Ali AF, Ho D, Wang B, Duffin J (2001): The contribution of chemoreflex drives to resting breathing in man. Exp Physiol 86:109-116

Mahamed S, Duffin J (2001): Repeated hypoxic exposures change respiratory chemoreflex control in humans. J Physiol 534:595-603

Mohan R, Duffin J (1997): The effect of hypoxia on the ventilatory response to carbon dioxide in man. Respir Physiol 108:101-115

Nutt D, Lawson C (1992): Panic attacks - a neurochemical overview of models and mechanisms. Br J Psychiatry 160:165-178

Pagani FD, Taveira da Silva AM, Hamosh P, Garvey TQ 3d, Gillis RA (1982): Respiratory and cardiovascular effects of intraventricular cholecystokinin. Eur J Pharmacol 78:129-132

Pain MCF, Biddle N, Tiller JWG (1988): Panic disorder, ventilatory response to $\mathrm{CO}_{2}$ 's respiratory variables. Psychosom Med 50:541-548

Papp LA, Klein DF, Gorman JM (1993a): $\mathrm{CO}_{2}$ hypersensitivity, hyperventilation, and panic disorder. Am J Psychiatry 150:1149-1157 
Papp LA, Klein DF, Martinez J, Schneier F, Cole R, Liebowitz MR, Hollander E, Fyer AJ, Jordan F, Gorman JM (1993b): Diagnostic and substance specificity of $\mathrm{CO}_{2}^{-}$ induced panic. Am J Psychiatry 150:250-257

Papp LA, Martinez JM, Klein DF, Coplan JD, Gorman JM (1995): Rebreathing tests in panic disorder. Biol Psychiatry 38:240-245

Perna G, Battaglia M, Garberi A, Arancio C, Bertani A, Bellodi $\mathrm{L}$ (1994): $\mathrm{CO}_{2} / \mathrm{O}_{2}$ challenge test in panic disorder. Psychiatry Res 42:159-171

Perna G, Berani A, Caldirola D, Bellodi L (1996): Family history of panic disorder and hypersensitivity to $\mathrm{CO}_{2}$ in patients with panic disorder. Am J Psychiatry 153:1060-1064
Read DJC (1967): A clinical method for assessing the ventilatory response to $\mathrm{CO}_{2}$. Austral Ann Med 16:20-32

Shlik J, Vasar V, Aluoja A, Kingisepp PH, Jagomägi K, Vasar E, Rägo L, Bradwejn J (1997): The effect of cholecystokinin tetrapeptide on respiratory resistance in healthy volunteers. Biol Psychiatry 42:206-212

Sinha SS, Coplan JD, Pine DS, Martinez JA, Klein DF, Gorman JM (1999): Panic induced by carbon dioxide inhalation and lack of hypothalamic-pituitary-adrenal axis activation. Psychiatry Res 86:93-98

Verburg K, Griez E, Meijer J, Pols H (1995): Discrimination between panic disorder and generalized anxiety disorder by $35 \% \mathrm{CO}_{2}$ challenge. Am J Psychiatry 152:1081-1083 